\title{
Avanços e desafios da sustentabilidade ambiental na Universidade Federal do Rio Grande do Norte
}

\section{Paula Gonçalves Serafini ${ }^{1}$,*, Jéssica Morais de Moura ${ }^{2}$, Anna Cláudia dos Santos Nobre ${ }^{3}$ e Júlio Francisco Dantas de Rezende ${ }^{1}$}

\begin{abstract}
${ }^{1}$ Universidade Federal do Rio Grande do Norte. Centro de Tecnologia. Programa de Pós-Graduação em Engenharia da Produção. Campus Universitário Lagoa Nova. Av. Senador Salgado Filho, 3000. Natal-RN, Brasil (CEP 59078-970). *E-mail: paulagserafini@gmail.com.

${ }^{2}$ Universidade Federal do Rio Grande do Norte. Departamento de Políticas Públicas. Programa de Pós-Graduação em Arquitetura e Urbanismo. Campus Universitário Lagoa Nova. Av. Senador Salgado Filho, 3000. Natal-RN, Brasil (CEP 59078-970).

${ }^{3}$ Universidade Federal do Rio Grande do Norte. Programa de Pós-Graduação em Administração. Campus Universitário Lagoa Nova. Av. Senador Salgado Filho, 3000. Natal-RN, Brasil (CEP 59078-970).
\end{abstract}

Resumo. 0 presente artigo aborda as práticas desenvolvidas pela Universidade Federal do Rio Grande do Norte (UFRN) na dimensão da sua gestão operacional. Num contexto em que os problemas ambientais têm cada vez mais sido objeto de discussão, esse artigo tem como objetivo investigar como uma instituição de ensino superior do nordeste do Brasil tem colaborado para redução dos impactos de sua atividade, de forma a priorizar ações ambientalmente sustentáveis. Este artigo proporcionou uma discussão sobre o tema, somando esforços às demais publicações no sentido de contribuir para o desenvolvimento de universidades ambientalmente sustentáveis. Adotando a metodologia de estudo de caso, a pesquisa foi desenvolvida a partir da análise documental e da realização de entrevista semiestruturada, onde foi identificado que a UFRN vem implantando uma série de programas voltados para a gestão integrada de resíduos, controle de qualidade da água, arborização, eficiência energética, comunicação e educação ambiental. Com diretrizes da sustentabilidade incluídas nos seus documentos institucionais e recebimento de prêmios que reconhecem as suas práticas, torna-se importante analisar as contribuições dessas ações no contexto de uma universidade sustentável. Como desafios a serem superados para incorporação da sustentabilidade como pilar estratégico, a pesquisa destaca a dificuldade de sensibilização e engajamento da comunidade universitária, sendo necessário empreender iniciativas que transformem a cultura organizacional. Por fim, a pesquisa

Recebido

09/06/2021

Aceito

$24 / 11 / 2021$

Disponível on line $24 / 11 / 2021$

Publicado

$31 / 12 / 2021$

Acesso aberto

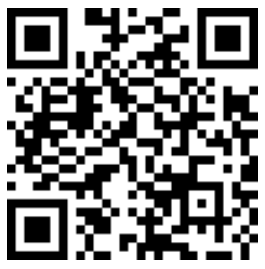

ISSN 2359-1412/RBGAS-2021-0071/2021/8/20/6/1349

Rev. Bras. Gest. Amb. Sustent.

http://revista.ecogestaobrasil.net 
permite contribuir com o tema de uma maneira mais ampla, reunindo boas práticas que devem ser disseminadas e incorporadas por outras instituições.

Palavras-chave: Sustentabilidade ambiental; Universidade; Gestão; Estudo de caso.

Abstract. Advances and challenges of environmental
sustainability at the Federal University of Rio Grande Norte. This paper addresses the practices developed by the Federal University of Rio Grande do Norte (UFRN) in the dimension of its operational management. In a context in which environmental problems have increasingly been the object of discussion, this article aims to investigate how a higher education institution in northeastern Brazil has collaborated to reduce the impacts of its activity in order to prioritize environmentally sustainable actions. This article provided a discussion on the subject, adding efforts to other publications to contribute to the development of environmentally sustainable universities. Adopting the case study methodology, the research was developed from documental analysis and semi-structured interview, where it was identified that UFRN has been implementing a series of programs aimed at integrated waste management, water quality control, afforestation, energy efficiency, communication and environmental education. With sustainability guidelines included in its institutional documents and receiving awards that recognize its practices, it is important to analyze the contributions of these actions in the context of a sustainable university. As challenges to be overcome for the incorporation of sustainability as a strategic pillar, the research highlights the difficulty of sensitization and engagement of the university community, and it is necessary to undertake initiatives that transform the organizational culture. Finally, the research allows contributing to the theme in a broader way, bringing together good practices that should be disseminated and incorporated by other institutions.

Keywords: Environmental sustainability; University; Management; Case study.

\footnotetext{
D 0000-0002-0826-353X

Paula Gonçalves

Serafini

(1) 0000-0001-8059-6294

Jéssica Morais de

Moura

(1) 0000-0003-1351-4265

Anna Cláudia dos

Santos Nobre

(D) 0000-0001-7505-7480

Júlio Francisco Dantas

de Rezende
}

\section{Introdução}

No contexto atual em que as questões ambientais assumiram notória relevância, é fundamental reconhecer o papel que as Instituições de Ensino Superior (IES) exercem na sociedade, disseminando conhecimento e potencializando a forma adequada de promover o desenvolvimento social, econômico e ambiental. Recentemente, assiste-se a um movimento de reformulação do modelo de ensino e de gestão das universidades, as quais passam a incorporar noções de sustentabilidade em todos os campos de atuação, inserindo-a como pilar estratégico nas atividades de ensino, pesquisa, extensão e manutenção da própria instituição (Zulpo et al., 2020). 
Destaca-se, portanto, que, pelo papel que desempenha , as universidades têm a missão de fomentar o pensamento crítico , incluindo a disseminação da consciência sustentável nas suas atividades de ensino, pesquisa e extensão, bem como na sua própria gestão operacional. Essa tendência é, conforme apontamentos de Velasquez et al. (2006), denominada de "Universidade Sustentável" e se aplica as instituições de ensino superior que estão preocupadas em minimizar os impactos negativos de sua atuação, adotando ações corretivas e mitigadoras em prol de estilos de vida mais sustentáveis. Estudos e pesquisas têm discutido esse tema em todo o mundo, sendo crescente a análise das práticas de sustentabilidade que vêm sendo desenvolvidas pelas IES. Como exemplo disso, destaca-se a pesquisa desenvolvida por Santa e Pfitscher (2016), os quais realizaram uma análise internacional sobre o tema, apontando as principais características de universidades que podem ser consideradas sustentáveis. As autoras evidenciam que essas instituições têm buscado adaptar-se ao conceito de sustentabilidade, propondo diretrizes para a incorporação desse tema na rotina de gestão institucional.

Sobre o conceito de universidade sustentável Guimarães e Bonilla (2018) ressaltam que ainda não há um consenso para o termo, evidenciando que as próprias instituições devem avaliar os principais aspectos que a definem como instituição sustentável. É importante frisar que o tema da sustentabilidade não se limita apenas a uma dimensão ambiental, mas do contrário, incorpora diversas ações que se relacionam aos aspectos sociais, econômicos e institucionais. Existem pesquisas diversas que abordam esse conjunto de ações de forma articulada e outras que enfatizam apenas uma dimensão do aspecto sustentável, tal como se apresenta com esse estudo que tem como enfoque a dimensão da sustentabilidade ambiental.

Essa perspectiva no cenário brasileiro, segundo Tauchen e Brandli (2006) e reforçada por Machado et al. (2013) foram agrupadas em duas principais correntes que explicam o papel das IES no que se refere a temática do desenvolvimento sustentável : a primeira, analisa a sustentabilidade propagando a missão de formar alunos que tenham consciência da agenda ambiental e da necessidade de preservação do meio ambiente; já a segunda corrente, aborda a esfera gerencial da universidade, existindo a preocupação de gerir adequadamente a utilização e o descarte de recursos , requerendo, assim, a implementação de Sistemas de Gestão Ambiental (SGA) em seus campi universitários.

Diante dessa perspectiva, o presente artigo busca investigar como uma instituição de ensino superior do nordeste do Brasil tem colaborado para redução dos impactos de sua atividade de forma a priorizar ações ambientalmente sustentáveis. A pesquisa enfoca como estudo de caso a experiência da Universidade Federal do Rio Grande do Norte (UFRN), a qual tem se destacado na implementação de uma série de ações que abordam o tema da sustentabilidade. Desde 2010 a universidade vem incorporando práticas que estão preocupadas com o desenvolvimento mais sustentável, incluindo na elaboração de seus planos e documentos institucionais, orientações que visam propor uma política de sustentabilidade ambiental em todas as suas ações. Essas informações podem ser percebidas quando se analisa o histórico de iniciativas desenvolvidas pela instituição, a qual desenvolveu políticas e planos para direcionar o tratamento do tema, além de ter aderido e acompanhar periodicamente as diretrizes da Agenda Ambiental na Administração Pública (A3P). Esse reconhecimento já foi tratado por Salviano et. al (2020) o qual identificou que a UFRN vem solidificando pilares que facilitam e possibilitam tornar uma universidade ambientalmente sustentável, o que justifica a importância de se ter um estudo de caso que detalhe tais ações e sirva como diretriz estimuladora dessa prática em outras instituições de ensino.

Os objetivos desse artigo, portanto, consistem em apresentar como a UFRN está organizada no que se refere à sustentabilidade ambiental, levantando as ações que vêm sendo desenvolvidas no âmbito da gestão operacional da instituição para se tornar mais sustentável e contribuir com o meio ambiente. Considerando os aspectos das atividades e 
processos sustentáveis da própria universidade é que se estrutura o presente artigo, sendo utilizada a análise documental e a realização de entrevista semiestruturada para analisar o processo de implementação das diretrizes de sustentabilidade ambiental que foram adotadas pela UFRN.

Sobre a estrutura do artigo, o mesmo está dividido em cinco seções, incluindo esta introdução que se propôs a apresentar o contexto geral do tema e os objetivos da pesquisa. A seção dois se destina a apresentar o referencial teórico levantado, identificando a evolução da temática da sustentabilidade nas universidades. Já a seção três, apresenta a metodologia do artigo, enfatizando os procedimentos de pesquisa que permitiram realizar o estudo de caso com a Universidade Federal do Rio Grande do Norte. A seção quatro do artigo, discute os achados da pesquisa, refletindo sobre as práticas de sustentabilidade implementadas pela UFRN e discorre sobre os desafios e perspectivas que ainda se apresentam à instituição. Por fim, a quinta e última seção do trabalho, apresenta as consideraçõe s finais, relacionando os dados levantados com os referenciais abordados, permitindo assim gerar uma contribuição acerca da importância da adoção de práticas de sustentabilidade nas universidades.

\section{Sustentabilidade ambiental nas universidades}

Para contextualizar as questões ambientais e a sua evolução é preciso voltar um pouco no tempo e perceber, historicamente, a velocidade com que os impactos ambientais em um nível global vêm ocorrendo. O desenvolvimento econômico do último século degradou e poluiu muito ao meio ambiente e, com isso, ocorreu uma utilização abusiva de recursos naturais, de forma desenfreada. Em virtude dessas escolhas, é possível identificar diversas consequências que este modelo de desenvolvimento trouxe para sociedade, se refletindo em graves problemas ambientais.

Diante dessa realidade, o desenvolvimento sustentável vem sendo um tema cada vez mais presente em toda sociedade e, de acordo com apontamento de Barbieri e Cajazeira (2012, p.67), as instituições, neste contexto, devem buscar se tornar sustentáveis, isto é, "alcançar seus objetivos atendendo, simultaneamente, os seguintes critérios: equidade social, prudência ecológica e eficiência econômica".

O desenvolvimento sustentável passa, então, a ser um pilar norteador de diversas ações, significando um tipo de desenvolvimento que satisfaz as necessidades da geração presente sem comprometer a capacidade das gerações futuras de suprir as suas próprias necessidades. Essa premissa, nas palavras de Gazzoni et al. (2018, p. 53) significa que "o desenvolvimento sustentável não se trata de uma escolha entre a proteção ambiental e o progresso social, mas de um esforço maior para desenvolvimento econômico e social que seja compatível com a proteção ambiental".

Adotando essa perspectiva, questiona-se como as instituições de ensino têm colaborado com a modificação de um pensamento que, anteriormente, não estava atento aos problemas da degradação ambiental e que, agora, prioriza um caráter mais sustentável de utilização desses recursos. É nesse contexto que se adota a premissa de que as universidades são tanto parte do problema da sustentabilidade como parte da solução, já que essas instituições de ensino podem ser consideradas pequenos núcleos urbanos e, por isso, devem gerenciar diversos projetos que implicam na melhor utilização dos recursos naturais, bem como na diminuição dos impactos ambientais oriundos dessas atividades.

As universidades devem, assim, atuar em múltiplas vertentes, considerando a sistematização de práticas de sustentabilidade ambiental que compreendam diversos aspectos, passando pelas atividades/processos sustentáveis no Campus; pesquisas sobre o tema da sustentabilidade; cooperação entre as instituições; extensão à comunidade; currículos sustentáveis e geração de relatórios de sustentabilidade (Silva e Almeida, 2019). Nesse sentido, Fonseca Filho et al. (2018, p. 17) destacam: 
O debate sobre desenvolvimento sustentável se estendeu para as instituições universitárias, as quais, enquanto agentes formadores e educadores sociais, não poderiam se isentar das responsabilidades ambientais e têm aderido ao movimento em prol do uso responsável dos recursos naturais.

No cenário nacional e no âmbito da gestão operacional dessas instituições, Pegorin et al. (2014) reforçam a concepção de que as instituições públicas brasileiras vêm sendo pressionadas a implementarem um sistema de gestão ambiental. Dentre as iniciativas que estão sendo colocadas em práticas, verifica-se o estímulo ao uso racional da água, adoção de fontes renováveis de energia, disposição adequada dos resíduos sólidos gerados pela instituição, implementação de programas de reciclagem e conscientização dos materiais que são descartados. Existem ainda diversas outras formas de implementar projetos que direcionem a uma prática mais sustentável, de modo que as instituições de ensino possam instituir normativos e políticas que as direcionem para uma atuação ambientalmente equilibrada, tornando-se referência no modo como lidam com seus projetos sustentáveis. Sobre esse assunto Lara (2012, p. 1647) destaca:

\section{[...] as universidades aparecem com seu papel transformador educador , construindo modelos para a formação do pensamento sustentável crítico, adotando medidas que levam a um sistema de gestão ambiental da própria instituição , bem como conceitos inovadores para a disseminação da consciência sustentável entre docentes, discentes e toda a comunidade acadêmica.}

Decorrente desse pensamento, em todo o mundo, diversas instituições de ensino passaram a incorporar práticas relacionadas ao desenvolvimento sustentável, assinando declarações e tratados que buscam legitimar a sua atuação. Trabalho desenvolvido por Silva e Almeida (2019) destaca que práticas de avaliação da sustentabilidade em instituições de ensino têm sido cada vez mais frequentes, sendo produzidos estudos tanto em âmbito internacional quanto nacional. Para o caso brasileiro, Rohrich e Takahashi (2019) identificaram que a produção científica sobre o tema se traduz em estudos de caso que de um lado abordam a perspectiva do ensino e do outro enfatizam relatos operacionais da instituição.

No que se refere à evolução de como as práticas de sustentabilidade têm sido incorporadas as instituições, é importante compreender o processo histórico que tem implicado na adoção desse padrão. Esse tema tem sido discutido desde a década de 1970 e, de acordo com as referências de Treml et al. (2018), a Conferência das Nações Unidas sobre o Meio Ambiente Humano realizada em Estocolmo em 1972, é considerada um marco para o surgimento do conceito de desenvolvimento sustentável, que passou a vincular a questão ambiental também à social. A partir de então, surgiram diversas experiências em instituições de ensino preocupadas em implementar práticas voltadas ao desenvolvimento sustentável e, Oliveira et al. (2016), destacam que essas iniciativas passaram por uma maior formalização no início da década de 1990, quando foi realizada a Conferência Internacional em Talloires na França, a qual deu origem ao primeiro compromisso para incorporar a sustentabilidade ambiental em faculdades e universidades de todo o mundo. Atualmente, a Declaração Talloires já foi assinada por 519 instituições em 61 países, sendo 52 instituições brasileiras, inclusive a UFRN (Talloires Declaration Institutional Signatory List, 2021).

Outro marco que da sequência a esse processo, ocorreu em 1991 e foi realizada outra conferência, dessa vez na cidade de Halifax no Canadá, sendo estabelecida mais uma iniciativa internacional que colocou as universidades como responsáveis no processo de construção de políticas e ações para a sustentabilidade. Seguindo nessa trajetória e olhando para o ano de 1992, foi aprovada a definição do conceito de desenvolvimento sustentável na II Conferência das Nações Unidas sobre o Meio Ambiente e o 
Desenvolvimento (CNUMAD), realizada na cidade do Rio de Janeiro e que ficou conhecida como Eco-92. Nessa conferência, foi instituída a Agenda 21, contendo uma série de compromissos a serem realizados e, para as instituições de ensino, isso representou um novo momento de como as mesmas deveriam se portar em relação ao meio ambiente, tornando-as protagonistas na propagação de um futuro mais sustentável.

Em 1993 foi assinada a Declaração de Swansea com o intuito de desafiar um desenvolvimento mais sustentável, ponderando que para isso seria necessário a participação de toda sociedade. Ainda nesse ano, a International Association of Universities (IAU) promoveu a declaração de Kyoto, a qual enfatizou a dimensão ética da educação para o desenvolvimento sustentável. Diversas ações foram propostas, com o destaque para a necessidade de encorajar as universidades a rever as suas próprias operações de forma a refletir as melhores práticas de desenvolvimento sustentável (Souto, 2018).

Outras iniciativas ainda podem ser observadas, conforme sintetiza Termignoni (2012), apontando que, após a Eco-92, diversas articulações foram sendo estabelecidas pelas IES, tais como a Organização Internacional de Universidades pelo Desenvolvimento Sustentável e Meio Ambiente (OIUDSMA) em 1995; a Global Higher Education for Sustainability Partnership (GHESP), em 2000; a primeira Environmental Management for Sustainable Universities (EMSU), em 2005; e, em 2007, um acordo global das Nações Unidas conjuntamente com instituições acadêmicas estabeleceu a iniciativa Principles for Responsible Management Education (PRME), apresentando princípios básicos que visam a formar uma plataforma global no ensino de gestão sustentável.

A pesquisa de Oliveira et al. (2016) continuam a evolução, tendo realizado uma revisão sobre as conferências internacionais para a sustentabilidade em Instituições de Ensino Superior. De acordo com os autores em 2009 foi formalizada a Declaração de Turin sobre a Educação e Pesquisa para o Desenvolvimento Sustentável e Responsável, instituída pela G 8 University Network, destacando que o foco se dava sobre o reconhecimento do papel indispensável que as IES e organizações de pesquisas científicas desempenham para o suporte do desenvolvimento sustentável no â mbito global e regional. Já em 2011, as instituições de ensino celebraram a Declaração das Américas, enfatizando o papel de destaque das universidades na promoção das ações de sustentabilidade, reconhecendo essas instituições como incentivadora de outros atores sociais. Em 2012 foi a vez da declaração da Educação Superior para a RIO +20, abordar o papel central que as IES possuem com relação a temática da sustentabilidade.

Esse último enfoque abordado na Conferência das Nações Unidas sobre o Desenvolvimento Sustentável deu origem a discussão sobre a criação da Agenda 2030, que em 2015 viria a ser lançada e seria responsável por instituir um conjunto de 17 Objetivos de Desenvolvimento Sustentável (ODS), delegando a diversos atores a responsabilidade pelo seu alcance. As universidades foram reconhecidas nessa agenda como importantes instituições para o cumprimento do desenvolvimento sustentável, sem as quais não seria possível alcançar, de fato, aquilo que preconiza o desenvolvimento sustentável (SDSN, 2017).

\section{Sistema de Gestão Ambiental nas universidades}

Abordado esse processo histórico que demonstra como o tema de inclusão da sustentabilidade nas universidades foi evoluindo em todo o mundo, se faz importante refletir sobre as práticas de gestão ambiental que tais instituições vêm implementando para responder as pressões de melhor promover o gerenciamento dos seus recursos. Nessa perspectiva, a literatura da sustentabilidade e da gestão ambiental nas universidades aponta que essas instituições devem ser modelos para os estudantes e para a sociedade, devendo incentivar demais atores nesse processo e se mostrar como exemplo através de suas práticas (Ferranti e Jabbour, 2012). 
No que se refere às iniciativas empreendidas pelas instituições em âmbito da sua gestão operacional, destaca-se a importância das Instituições de Ensino Superior (IES) implementarem ações de gestão sustentável em sua própria rotina, tornando-se modelo de boas práticas e influenciando positivamente os demais atores da sociedade em prol de um desenvolvimento mais sustentável (Lara, 2012).

Nesse contexto, ressalta-se a emergência do Sistema de Gestão Ambiental (SGA), o qual é definido, conforme sintetiza Engelman et al. (2009), como um sistema que estabelece um conjunto de procedimentos a serem adotados com vistas a tornar uma organização ambientalmente equilibrada e preocupada em se mobilizar, interna e externamente, para se tornar referência na adoção de práticas menos prejudiciais ao meio ambiente.

Esse Sistema de Gestão Ambiental foi regulamentado pela ISO 14001, sendo esta uma importante ferramenta para garantir que empresas e instituições, sejam elas públicas ou privadas, implantem modelos que sigam os padrões de sustentabilidade. Essa norma permite ainda que sejam especificadas orientações para a elaboração de uma política ambiental, considerando o estabelecimento de estratégias, objetivos e metas que certifiquem práticas ambientalmente equilibradas. No Brasil, a norma é representada pela Associação Brasileira de Normas Técnicas (ABNT), intitulada como NBR ISO 14001, tendo aplicação de uso voluntário, porém, representando um diferencial para quem a aplica.

Nessa dimensão, um SGA numa universidade deve estar intrinsicamente ligado ao desenvolvimento de uma missão na instituição que seja compreendida por toda comunidade acadêmica, envolvendo estes atores na adoção de práticas ambientais sustentáveis que sejam planejadas, monitoradas e avaliadas, de modo a, de fato, tornar a gestão da instituição compromissada com tais aspectos do desenvolvimento.

\begin{abstract}
A implantação do SGA deve considerar as atividades de todos os departamentos , disciplinas e estruturas de gestão de uma instituição de ensino superior , incluindo no processo todos os stakeholders envolvidos direta ou indiretamente. Com relação ao sistema gerencial e administrativo da IES , deve-se elaborar um planejamento global, que crie uma identidade ambiental da instituição e também um planejamento local , centralizado em cada campus , considerando suas peculiaridades de gestão e funcionamento (Lara, 2012, p. 1651).
\end{abstract}

São apontados diversos motivos para que as universidades implantem o seu Sistema de Gestão Ambiental, sendo destacado por Tauchen e Brandli (2006) que essas instituições são responsáveis pela geração de resíduos sólidos, efluentes líquidos, consumo de recursos naturais, se assimilando a pequenos núcleos urbanos que recebem inputs e emitem outputs.

Sobre esse assunto, pesquisa realizada por Nolasco et al. (2006) destacou que, no Brasil, as iniciativas voltadas para a adoção de ações menos prejudiciais ao meio ambiente nas universidades ainda se dão de forma isolada, sendo observadas algumas experiências pontuais em grandes e mais antigas universidades estaduais e federais. Já Vaz et al. (2010) em sua pesquisa sobre as Instituições de Ensino Superior e o Sistema de Gestão Ambiental, destacaram que algumas das universidades brasileiras implantaram o Sistema de Gestão Ambiental, sendo a primeira experiência desenvolvida pela Universidade do Vale do Rio dos Sinos, no Rio Grande do Sul, por intermédio do projeto Verde Câmpus. Outras 12 universidades foram citadas pelos autores, os quais reforçam que as instituições, ao implementarem um sistema de gestão ambiental, podem obter inúmeros benefícios econômicos, sociais e ambientais, favorecendo, assim, a sustentabilidade de toda organização.

Outras experiências foram descritas por Machado et al. (2013), tendo sido realizado um survey com 75 instituições e evidenciado 22 práticas de gestão ambiental 
que demonstram experiências exitosas e também evidenciam as barreiras para 0 desenvolvimento dessas ações nas instituições de ensino. Alves et al. (2018) numa outra perspectiva, selecionaram modelos de gestão ambiental que obtiveram maior êxito em IES, sendo desenvolvida uma revisão sistemática de cunho qualitativo e quantitativo que identificou um total de seis pesquisas relevantes para serem analisadas nesse tema.

Fonseca Filho et al. (2018) trazem um detalhamento da Universidade Federal do Sul da Bahia, apontando que essa instituição implantou uma Pró-reitora de sustentabilidade e integração social, a qual passou a desenvolver diversas ações voltadas para a consolidação de um sistema de gestão ambiental.

Rohrich e Takahashi (2019), sobre estudo bibliométrico das publicações nacionais acerca da sustentabilidade ambiental em Instituições de Ensino Superior, destacaram que as experiências podem ser agrupadas em duas vertentes, sendo uma relativa ao lado acadêmico, e a outra relativa ao lado operacional da gestão. De acordo com os autores, foram selecionados 16 artigos que abordam iniciativas de IES que estão preocupadas na implantação de práticas de responsabilidade socioambiental , compreendendo as operações físicas e serviços oferecidos à comunidade interna e externa

Sobre os benefícios de implantação de um SGA, é valido destacar que além dos efeitos sociais e pedagógicos, verifica-se redução de custos energéticos, de consumo de materiais e insumos e aumento de produtividade. Para as universidades, a implantação de um sistema desse porte reforça a preocupação da instituição não apenas com a educação formal, mas também com as boas práticas de sustentabilidade . Machado et al. (2013) reforçam essas vantagens, apontando que a implantação da sustentabilidade nas instituições de ensino pode melhorar o seu desempenho, uma vez que o SGA pode reduzir a quantidade de materiais e energia utilizados, implicando em economias.

Couto (2016) aprofundou nesse tema, destacando motivações e barreiras que levam as universidades a implantarem um sistema de gestão ambiental. Como principal questão apontada, verifica-se que a implementação dessas ações permite que a instituição desenvolva metas e políticas ambientais que lhe possibilitam gerir o impacto ambiental dos seus serviços, produtos e operações.

Diversos motivos podem ser numerados como benéficos, sendo relevante destacar que, externamente, a instituição sofre pressão por parte da sociedade para se tornar uma organização que possui práticas ambientais em sintonia com o meio ambiente. Afinal, do que adiantaria uma universidade fomentar pesquisas e inovação e abordar a necessidade de diminuir os impactos ambientais, se ela mesma não for capaz de promover uma gestão interna que considere o impacto da utilização de recursos? Como fatores internos, ao implantar um sistema de gestão ambiental, a universidade melhora a sua imagem perante a sociedade e reduz custos com processos produtivos, se tornando mais eficiente nas suas operações e na utilização de recursos como a água, a eletricidade ou o gás. Isso culmina com a redução da sua pegada ambiental (Couto, 2016).

Em síntese e conforme discutido, verifica-se que a temática da sustentabilidade ambiental foi gradativamente alcançando seu espaço nas instituições de ensino, sendo hoje um paradigma a ser seguido pelas universidades que estão preocupadas não só em fomentar o pensamento crítico, mas também por consistirem em verdadeiros exemplos de instituições ambientalmente sustentáveis. Interessa, portanto, conhecer cada vez mais as experiências que têm sido desenvolvidas, analisando e disseminando caminhos que podem ser seguidos por outras instituições.

\section{Metodologia}

Diante da necessidade de examinar práticas de sustentabilidade ambiental que vêm sendo desenvolvidas em universidades, essa pesquisa se classifica quanto aos seus objetivos como exploratória e, de acordo com apontamentos de Gil (2018), esse tipo de 
pesquisa se caracteriza por proporcionar maior familiaridade com um problema permitindo torná-lo mais explícito, bem como fomentar o aprimoramento de ideias. Ainda segundo Gil (2018), a pesquisa exploratória possui um planejamento bastante flexível e, na maioria das vezes, envolve: "a) levantamento bibliográfico; b) entrevistas com pessoas que tiveram experiências práticas com o problema pesquisado; e c) análise de exemplos que estimulem a compreensão" (Gil, 2018, p. 41).

Esse tema, embora apresente notória relevância, ainda se encontra em desenvolvimento. A maioria das pesquisas até então publicadas possuem natureza de estudo de caso e, no que trata especificamente das práticas de sustentabilidade nas universidades, Zulpo et al. (2020) consideram que as publicações do tema se encontram em evolução, tendo sido realizada uma revisão sistemática com 28 trabalhos publicados em periódicos. Rohrich e Takahashi (2019) realizaram um estudo bibliométrico e reforçaram a ausência de uma publicação nacional especifica sobre a temática, sendo analisados cerca de 27 artigos que abordam cases de instituições de ensino brasileiras.

Sendo mais uma contribuição para essa área, esse estudo se classifica como do tipo estudo de caso, sendo esse um "estudo profundo e exaustivo de um ou poucos objetos, de maneira que permita seu amplo e detalhado conhecimento" (Gil, 2018, p. 54). Essa abordagem envolve um estudo no ambiente ou no contexto contemporâneo da vida real, permitindo realizar correlações que se tornem referências na execução de determinadas ações (Yin, 2009).

No que se refere aos procedimentos metodológicos que orientaram a construção desse trabalho, destaca-se que o mesmo se fundamentou numa pesquisa bibliográfica, reunindo os autores que abordam a temática da sustentabilidade como questão central a ser discutida pelas universidades, enfatizando aspectos da implementação de um sistema de gestão ambiental por essas instituições de ensino.

Além desse referencial teórico, o trabalho sistematizou uma pesquisa documental do caso de estudo, analisando políticas, normativos e relatórios disponibilizados pela UFRN e que tratam dos aspectos de sustentabilidade ambiental que foram implementados pela instituição. Entre os documentos consultados, destaca-se o Plano de Desenvolvimento Institucional (PDI), o Plano de Gestão, o Relatório Anual de Gestão, a Política Ambiental e o Plano de Gestão de Logística Sustentável (PLS).

Foi combinada ainda a técnica de entrevista semiestruturada, sendo esse um método de recolhimento de dados que parte de uma interação verbal entre o entrevistador e o respondente. As perguntas foram parcialmente formuladas, permitindo flexibilidade no momento de coleta de dados, os quais foram aprofundados por elementos apresentados pelo próprio entrevistado. A entrevista foi realizada em janeiro de 2020 junto à Professora Doutora Ângela Maria Paiva Cruz, Reitora da Universidade no período de 2011 a 2019 e atualmente Assessora do Gabinete do Reitor, sendo a mesma responsável por iniciar a implementação das diretrizes da sustentabilidade na instituição, inclusive com iniciativas premiadas pelo Ministério do Meio Ambiente e pela Organização das Nações Unidas.

Os resultados são apresentados a seguir na forma de descrição de informações, contendo a apresentação da instituição, bem como a reflexão das práticas de sustentabilidade que passaram a fazer parte do cotidiano dessa universidade.

\section{Resultados e discussão}

Esta seção do artigo destina a apresentar a Universidade Federal do Rio Grande do Norte (UFRN) no contexto da implementação das práticas de sustentabilidade em sua gestão operacional. Para tanto, inicialmente apresenta-se a instituição, sua estrutura e o seu processo de criação. Em seguida, descreve-se como a Universidade está organizada no que se refere aos seus documentos institucionais, enfatizando, nesse contexto, aspectos da

Rev. Bras. Gest. Amb. Sustent., 2021, vol. 8, n. 20, p. 1333-1347. 
sustentabilidade. Por fim, na terceira parte, são discutidas as práticas de sustentabilidade implementadas pela instituição, analisando os desafios que ainda devem ser superados.

\section{Apresentação da instituição}

A UFRN é uma instituição de caráter público, organizada sob a forma de autarquia de regime especial e mantida pelo Ministério da Educação, localizada na cidade de Natal e com campis em outros municípios do Rio Grande do Norte. Foi criada em 25 de junho de 1958, por meio de lei estadual e, posteriormente foi federalizada em 18 de dezembro de 1960, passando também por um processo de reforma universitária em 1968 que culminou na formação da sua atual estrutura, a qual é composta por Conselhos Superiores, Reitoria, Unidades Acadêmicas Especializadas e os Núcleos de Estudos Interdisciplinares.

Atualmente a instituição conta com 8 Centros Acadêmicos, compreendendo as áreas de Biociências; Ciências da Saúde; Ciências Exatas e da Terra; Ciências Humanas, Letras e Artes; Ciências Sociais Aplicadas; Educação e Ensino; e Tecnologia. Ofertando 379 cursos de graduação e pós-graduação, cerca de 43 mil alunos estão matriculados na instituição que conta ainda com um número de 5.462 servidores, entre técnicoadministrativos e docentes efetivos, além dos professores substitutos e visitantes.

A Universidade, em 2020, foi considerada a quarta melhor Universidade do Nordeste, de acordo com o ranking das melhores instituições de ensino superior divulgado pela World University Ranking, ocupando a 25a colocação no Brasil, e tendo papel estratégico no desenvolvimento nacional e regional. Quanto a qualidade da instituição e, de acordo com Índice Geral de Cursos da Instituição (IGC), indicador de qualidade de instituições de educação superior e que varia de 0 a 5, a UFRN vem mantendo o conceito 4 desde que esse índice foi instituído pelo MEC em 2007, tendo um histórico acima da média nacional.

\section{Documentos Institucionais e a organização da Universidade}

Para pensar o tema da sustentabilidade ambiental, a Universidade deve incorporar essas diretrizes em todo seu planejamento, partindo da dimensão estratégica, passando pelo nível tático e chegando até o nível operacional, isto é, quando pode ser visualizado em pequenas ações geridas pelos seus centros de ensino. Numa orientação geral formulada pelo Ministério da Educação (MEC), o planejamento estratégico se dá por meio da elaboração do Plano de Desenvolvimento Institucional (PDI), elaborado para um período de 5 anos, sendo esse o documento que identifica a Instituição de Ensino Superior (IES), no que diz respeito à sua filosofia de trabalho, à missão a que se propõe, às diretrizes pedagógicas que orientam suas ações, à sua estrutura organizacional e às atividades acadêmicas que desenvolve ou que pretende desenvolver.

No caso específico da UFRN, o processo de planejamento é constituído de três níveis hierárquicos, compreendendo, no nível estratégico o Plano de Desenvolvimento Institucional (PDI) que define os rumos da Universidade contemplando a sua missão e visão de futuro, os objetivos e metas globais, além do Projeto Pedagógico Institucional (PPI), orientador da política acadêmica da UFRN. No nível tático, o planejamento é constituído do Plano da Gestão da Administração Superior e da Direção de Centros e de Unidades Acadêmicas, contendo as decisões de caráter geral da UFRN, e específicas no caso dos Centros e Unidades, para um período definido, e tem o compromisso de manter os avanços alcançados e o desafio de estabelecer novas conquistas articuladas ao PDI. Já o nível operacional, efetiva-se mediante a realização dos Planos Trienais, dos Projetos Pedagógicos dos Cursos e dos Projetos de Pesquisa e de Extensão, compatíveis com os outros níveis do processo de planejamento. A UFRN propôs ao MEC que o PDI da instituição tenha vigência de 10 anos, sendo realizada uma avaliação e revisão de metas a cada cinco anos. 
Sobre o processo de monitoramento e avaliação dessas ações, ressalta-se que o planejamento estratégico e o planejamento em nível tático da UFRN estão baseados na definição de metas de longo prazo estabelecidas no PDI e de metas anuais definidas a partir das linhas de ação dos eixos programáticos do Plano de Gestão. Essas metas são cadastradas no Sistema Integrado de Gestão de Planejamento e de Projetos (SIGPP) e o seu acompanhamento e avaliação são realizados a partir de indicadores que aferem os resultados alcançados e o cumprimento dos objetivos institucionais a partir da análise e discussão periódica pela Administração Superior dos percentuais de execução dessas metas.

Outros documentos e normativos também são elaborados visando dar transparência a esse processo, tais como o relatório de gestão e as diversas políticas formuladas para atendimento de questões específicas, podendo-se citar a acessibilidade, a segurança, a comunicação, o meio ambiente, entre outras. Esses registros estão disponíveis no site da instituição que busca sempre disseminar o acesso ao conteúdo regulamentado.

Aprofundando a questão da sustentabilidade nos normativos instituídos, destacase que a UFRN vem desenvolvendo uma série de documentos que pautam o tema em toda sua gestão operacional. Com uma Diretoria de Meio Ambiente vinculada à Superintendência de Infraestrutura (SIN) e consolidada em 2009, a instituição passou a ter uma unidade responsável pelo planejamento, implantação e execução de programas e projetos voltados para a sustentabilidade ambiental na Universidade, passando a ser executado diversos projetos que atenuam o impacto ambiental das ações desenvolvidas, tais como: atividades de monitoramento da qualidade e uso racional da água; controle de zoonoses e insetos vetores; limpeza pública e gestão integrada de resíduos sólidos domésticos, perigosos e da construção civil; arborização urbana e ornamental; tratamento de efluentes e reuso de esgoto tratado para irrigação e compactação de solo; eficiência energética; contratações sustentáveis; além de educação ambiental aplicada de modo transversal a cada atividade desenvolvida.

Nessa mesma dimensão, o ano de 2014 também marcou essa trajetória, sendo realizada a adesão da UFRN à Agenda Ambiental na Administração Pública (A3P) e tendo uma comissão gestora designada pela Portaria no 166/14-R, de 28 de janeiro de 2014. A A3P é um programa que busca incorporar os princípios da responsabilidade socioambiental nas atividades da Administração Pública, através do estímulo a determinadas ações que vão, desde uma mudança nos investimentos, compras e contratações de serviços pelo governo, passando pela sensibilização e capacitação dos servidores, pela gestão adequada dos recursos naturais utilizados e resíduos gerados, até a promoção da melhoria da qualidade de vida no ambiente de trabalho. Ainda em 2014 e decorrente dessas ações, a Universidade recebeu o Selo Verde da A3P emitido pelo Ministério de Meio Ambiente, reconhecendo o seu empenho e compromisso socioambiental.

No ano de 2016, foi elaborada uma cartilha temática da A3P, voltada para o Uso Racional dos Recursos e Bens Públicos, sendo disponibilizada pela UFRN em 2017 a plataforma REUSE. Essa plataforma nasceu como uma solução para otimizar o processo de gestão de patrimônio da instituição, possibilitando que os servidores adotem algumas práticas sustentáveis em seu dia a dia e permitindo divulgar na rede aqueles materiais que não utilizam mais para que outros servidores possam utilizá-lo (Figura 1). 


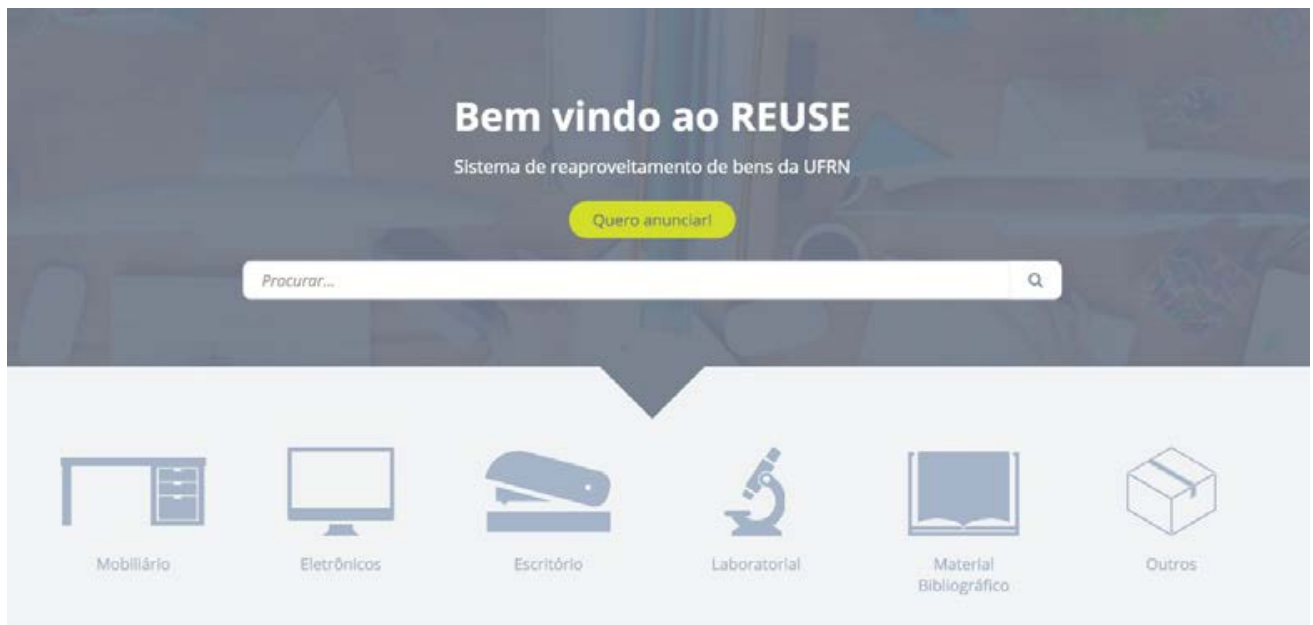

Figura 1. Portal REUSE da UFRN. Fonte: UFRN, 2021.

Outro importante marco instituído se refere ao Plano de Gestão de Logística Sustentável da UFRN (PLS-UFRN), aprovado em 21 de dezembro de 2017, pela Resolução 077/2017. O plano estabeleceu, entre outras medidas, práticas de sustentabilidade e racionalização no uso de materiais e serviços e é constituído por um conjunto de 9 Planos de Ação, cada um contendo metas gerais que abrangem todos os campi e metas específicas compatíveis com a realidade de cada campus, direcionadas para a implantação, monitoramento e avaliação de práticas de sustentabilidade e racionalização do uso de materiais e serviços (Figura 2). Com intuito de promover o monitoramento nesse das ações previstas no plano, a UFRN desenvolveu o indicador para mensurar os resultados e evolução na execução dessas práticas (Figura 3).

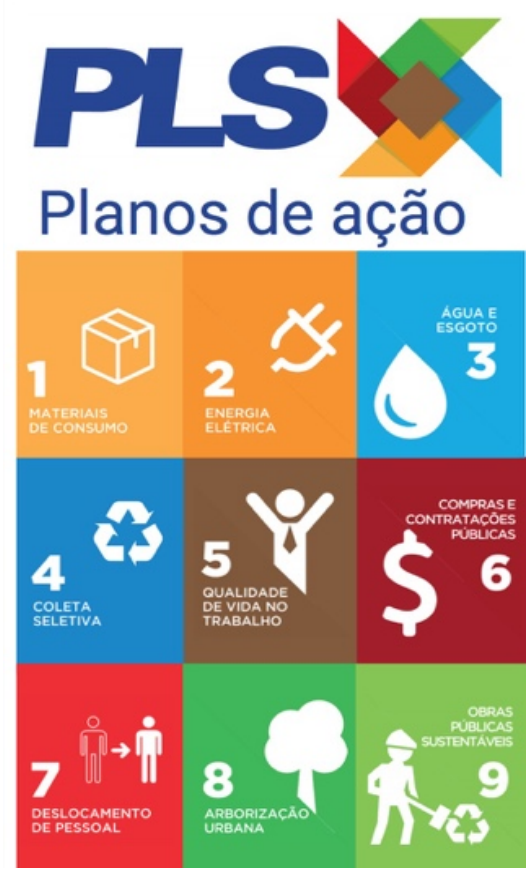

Figura 2. Planos de Ação do Plano de Gestão da Logística Sustentável da UFRN. Fonte: UFRN (2021). 


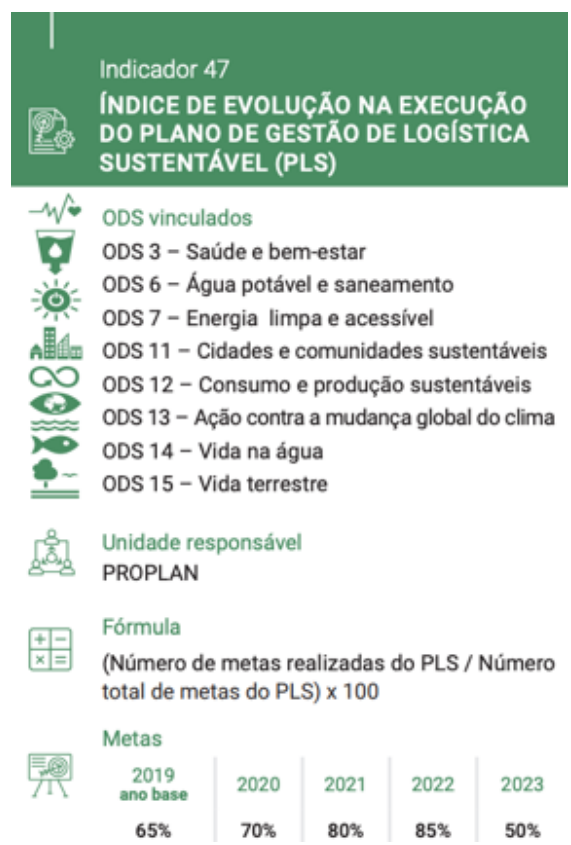

Figura 3. Índice de Evolução Na Execução do Plano de Gestão de Logística Sustentável (PLS). Fonte: Plano de Gestão 2019-2023 (UFRN, 2021).

Em 2018, a UFRN avançou mais um passo com a criação da Política Ambiental da instituição de ensino, aprovada pela Resolução CONSEPE no 042, de 10 de abril de 2018. Com base na Política Nacional do Meio Ambiente, a Política Ambiental da UFRN traz um conjunto de princípios e diretrizes que visam a implantar ou a regulamentar ações institucionais com o objetivo de promover o desenvolvimento sustentável na Universidade e na sociedade, na perspectiva de um ambiente saudável e ecologicamente equilibrado. Essa iniciativa começou a ser pensada ainda no ano de 2002, quando um grupo da UFRN apresentou à Administração Superior uma "Proposta de Política Ambiental para a UFRN", visando garantir que os impactos resultantes de todas as atividades fossem minimizados a ponto de que nenhuma atividade desenvolvida pela instituição viesse a impactar os ambientes onde ela está inserida além dos limites considerados aceitáveis.

Dando ainda mais notoriedade às questões de sustentabilidade, a UFRN desenvolveu o Portal de Meio Ambiente, tendo sido esse idealizado como projeto de extensão em 2011 e se configurando no primeiro meio de comunicação eletrônica produzido pela Diretoria de Meio Ambiente. Em 2019, o portal foi reformulado, passando a ter como objetivo primário informar à comunidade universitária como o meio ambiente é tratado na UFRN e quais as ações ambientais e de sustentabilidade realizadas rotineiramente pela Superintendência de Infraestrutura e suas diretorias.

\section{Analisando as práticas de sustentabilidade ambiental da UFRN}

A UFRN, conforme já observado, possui práticas e ações de sustentabilidade ambiental bem consolidadas e em constante processo de melhoria. No entanto, esse processo pode ser visualizado com mais clareza a partir do ano de 2010, quando a sustentabilidade deixou de ser objeto de discussão apenas nas salas de aula e passou a fazer parte da gestão operacional da instituição. Exemplo disso pode ser evidenciado quando se analisa a missão da Universidade, divulgada nos PDIs e Plano de Gestão, indicando que a palavra sustentabilidade apareceu como pilar norteador de todas as ações promovidas pela instituição (Figura 4). 
MISSÃO UFRN

PDI 1999 - 2008

A missão da UFRN, como instituição pública, é educar, produzir e disseminar o saber universal, contribuir para o desenvolvimento humano, comprometendo-se com a justiça social, a democracia e a cidadania.
MISSÃO UFRN

PDI 2010 - 2019
A missão da Universidade Federal do Rio Grande do Norte, como instituição pública, é educar, produzir e disseminar o saber universal, preservar e difundir as artes e a cultura e contribuir para o desenvolvimento humano, comprometendo-se com a justiça social, a sustentabilidade socioambiental, a democracia e a cidadania.

Figura 4. Missão da UFRN. Fonte: PDI 1999-2008 e PDI 2020-2029.

Olhando para a missão proposta no PDI de 1999 a 2008, verifica-se a ausência do pilar da sustentabilidade. Já em 2010, o novo PDI ressaltou que a instituição passou a organizar um conjunto de práticas que seriam implementadas. 0 tema sustentabilidade permeou todo o PDI, podendo ser também observado na visão que fora proposta, a qual destaca a sustentabilidade das ações como uma premissa básica. A versão atualizada do PDI da instituição (2020-2029) permaneceu com a mesma missão definida no PDI anterior, sendo assegurado os princípios de sustentabilidade. Outro exemplo observado, se refere aos objetivos presentes nesse documento, o qual contemplou a necessidade de incorporar às práticas acadêmicas e às ações administrativas o princípio de sustentabilidade: ambientalmente correto, economicamente viável, socialmente justo e culturalmente aceito.

Já na Política de Gestão 2015-2019, também se verificou a preocupação com o tema, observando a meta da implantação de Sistema Integrado de Gestão Ambiental, objetivando identificar os problemas ambientais da Instituição e estabelecer um plano de melhoria contínua na atenuação ou eliminação desses problemas através de uma Política Ambiental da UFRN.

Entre as estratégias definidas para o período de 2015-2019, destaca-se a criação de um Eixo Programático intitulado "Cidadania, inclusão social e sustentabilidade", com metas específicas de indução de atividades formativas relacionadas à sustentabilidade ambiental, direitos humanos, cultura de paz, tolerância e respeito às diferenças; e de consolidação da política de meio ambiente e sustentabilidade na UFRN. Para tanto, a UFRN propôs: i) criar um programa permanente que promova a educação para a sustentabilidade em seu sentido amplo; ii) priorizar ações que promovam a educação para a sustentabilidade; e iii) eliminar a aceitação e envio em papel de requisições, memorandos e outros documentos, observando o princípio da sustentabilidade ambiental.

Partindo para a análise do Plano de Gestão 2019-2023, verifica-se que as diretrizes de sustentabilidade continuam a fazer parte do planejamento institucional, sendo proposto o desafio de buscar uma gestão universitária eficiente e eficaz, com 0 desenvolvimento da sustentabilidade em todas as suas esferas : ambiental, social e econômica. Outro ponto que merece destaque é a vinculação desse plano de gestão aos Objetivos do Desenvolvimento Sustentável (ODS), que compõem a Agenda 2030 da Organização das Nações Unidas (ONU), o que demonstra a preocupação de desenvolver ações que, ao mesmo tempo, promovam qualidade de vida e garantam o futuro do planeta.

Esses princípios estão dispostos no Mapa Estratégico da UFRN (Figura 5), elaborado para o período de 2019 a 2023, sendo ressaltado no eixo do desenvolvimento institucional, um objetivo específico que está voltado para "Promover Sustentabilidade Energética, Ambiental e da Tecnologia da Informação" (Plano de Gestão da UFRN 20192023, p. 9). 


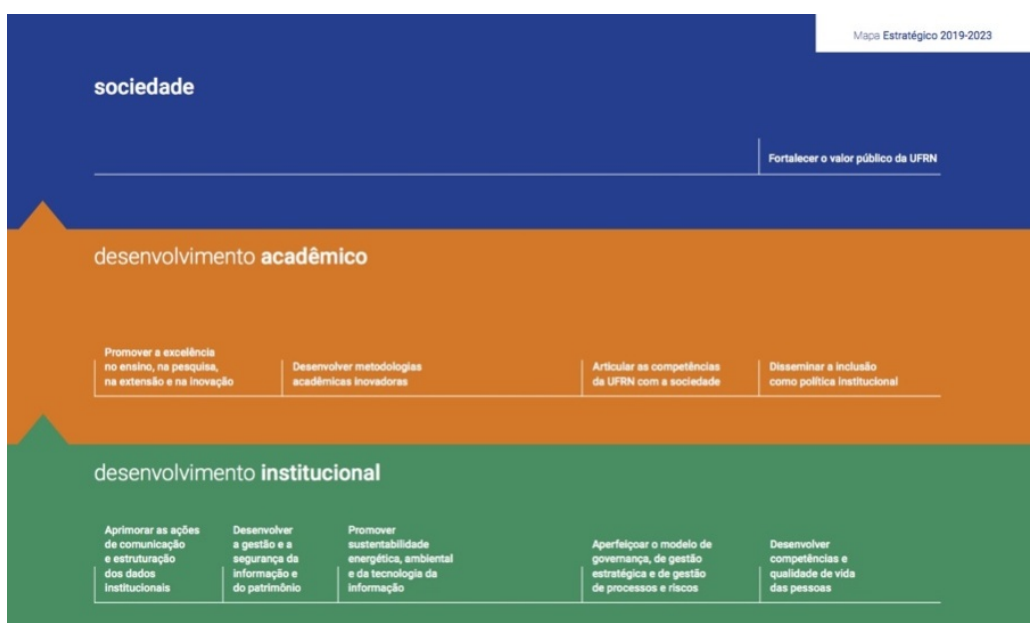

Figura 5. Mapa Estratégico da UFRN. Fonte: Plano de Gestão (2019-2023), UFRN.

Nesse documento são expressos também um conjunto de indicadores que permitem alcançar o objetivo desejado, sendo importante destacar para a perspectiva da sustentabilidade os seguintes indicadores: i) índice de consumo de energia ; ii) índice de evolução na execução do Plano de Gestão de Logística Sustentável (PLS); e iii) índice de tecnologia da informação e comunicação sustentável . Ressalta-se ainda que todos esses indicadores possuem metas e iniciativas estratégicas delimitadas, sendo possível verificar também a vinculação de cada um deles aos Objetivos do Desenvolvimento Sustentável proposto pela ONU (Figura 6).

\begin{tabular}{|c|c|c|c|c|c|c|c|c|c|c|c|}
\hline 鹏 & \multicolumn{5}{|c|}{$\begin{array}{l}\text { Indicador } 46 \\
\text { INDICE DE } \\
\text { CONSUMO DE ENERGIA }\end{array}$} & 90 & \multicolumn{5}{|c|}{$\begin{array}{l}\text { Indicador } 47 \\
\text { ÍNDICE DE EVOLUÇÃO NA EXECUÇÃo } \\
\text { DO PLANO DE GESTÃO DE LOGISTICA } \\
\text { SUSTENTAVEL (PLS) }\end{array}$} \\
\hline & \multicolumn{5}{|c|}{ ODS vinculados } & $-w 6$ & \multicolumn{5}{|c|}{ ODS vinculados } \\
\hline & \multicolumn{5}{|c|}{$\begin{array}{l}\text { ODS vinculados } \\
\text { ODS } 6 \text { - Água limpa e saneamento }\end{array}$} & 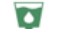 & \multicolumn{5}{|c|}{ ODS 3 - Saúde e bem-estar } \\
\hline o & \multicolumn{5}{|c|}{ ODS 12 - Consumo e produçăo responsáveis } & 潧: & \multicolumn{5}{|c|}{ ODS 6 - Água potável e saneamento } \\
\hline \multirow{2}{*}{ 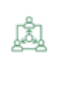 } & \multicolumn{5}{|c|}{ Unidade responsável } & A甩的 & \multirow{2}{*}{\multicolumn{5}{|c|}{$\begin{array}{l}\text { ODS } 11 \text { - Cidades e comunidades sustentáveis } \\
\text { ODS } 12 \text { - Consumo e produção sustentáveis } \\
\text { ODS } 13 \text { - Açăo contra a mudança global do clima }\end{array}$}} \\
\hline & \multicolumn{5}{|c|}{ INFRA } & @ & & & & & \\
\hline \multirow{3}{*}{ 堛 } & \multicolumn{5}{|l|}{ Fórmula } & $\widetilde{\infty}$ & \multicolumn{3}{|c|}{ ODS 14 - Vida na água } & & \\
\hline & \multirow{2}{*}{\multicolumn{5}{|c|}{$\begin{array}{l}\text { (Consumo de energia atual / Consumo de } \\
\text { energia do ano anterior }-1) \times 100\end{array}$}} & + & \multicolumn{5}{|c|}{ ODS 15 - Vida terrestre } \\
\hline & & & & & & 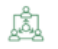 & \multicolumn{5}{|c|}{ Unidade responsável } \\
\hline \multirow[t]{2}{*}{ 笺 } & $\begin{array}{l}2019 \\
\text { ano base }\end{array}$ & 2020 & 2021 & 2022 & 2023 & & \multicolumn{5}{|l|}{ Förmula } \\
\hline & . & $15 \%$ & $.5 \%$ & $-5 \%$ & $-5 \%$ & $x=$ & \multicolumn{5}{|c|}{$\begin{array}{l}\text { (Número de metas realizadas do PLS / Número } \\
\text { total de metas do PLS) x } 100\end{array}$} \\
\hline (9) & \multicolumn{6}{|c|}{ Iniciativas estratégicas } & \multicolumn{5}{|l|}{ Metas } \\
\hline & \multicolumn{5}{|c|}{$\begin{array}{l}\text { Promover geraçăo de energias renováveis } \\
\text { (fotovoltaica); }\end{array}$} & 辰 & $\begin{array}{c}2019 \\
\text { ano base }\end{array}$ & 2020 & 2021 & 2022 & 2023 \\
\hline & \multicolumn{5}{|c|}{$\begin{array}{l}\text { Realizar acompanhamento e correçăo } \\
\text { do fator de potência; }\end{array}$} & & $65 \%$ & 70\% & $80 \%$ & $85 \%$ & $50 \%$ \\
\hline & \multirow{2}{*}{\multicolumn{5}{|c|}{$\begin{array}{l}\text { Realizar implantação de projetos eficientes, } \\
\text { como instalaçăo de lâmpadas de led e } \\
\text { motores mais eficientes; }\end{array}$}} & (อ) & \multicolumn{5}{|c|}{ Iniciativas estratégicas } \\
\hline & & & & & & & \multicolumn{5}{|c|}{$\begin{array}{l}\text { Promover reuniōes bimestrais de monitoramento } \\
\text { e controle com os responsáveis pelas metas; }\end{array}$} \\
\hline & \multirow{2}{*}{\multicolumn{5}{|c|}{ Promover programa de conscientizaçăo. }} & & $\begin{array}{l}\text { Promover } \\
\text { com a Cor }\end{array}$ & $\begin{array}{l}\text { uniōes e } \\
\text { ssăo Ge }\end{array}$ & $\begin{array}{l}\text { tratégica } \\
\text { cora do P }\end{array}$ & $\begin{array}{l}\text { trimestra } \\
\text { s; }\end{array}$ & \\
\hline & & & & & & & $\begin{array}{l}\text { Realizar ar } \\
\text { plano entr } \\
\text { comprome } \\
\text { sustentabi }\end{array}$ & $\begin{array}{l}\text { pla divul } \\
\text { toda a } \\
\text { mento } \\
\text { dade pre }\end{array}$ & $\begin{array}{l}\text { açäo/sen } \\
\text { nunidade } \\
\text { todos co } \\
\text { stas noc }\end{array}$ & 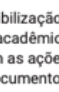 & $\begin{array}{l}\text { do } \\
\text { a para } \\
\text { de }\end{array}$ \\
\hline
\end{tabular}

Indicador 48
INDICE DE TECNOLOGIA DA
INFORMAÇĀO E COMUNICAÇĀO
SUSTENTAVEL

Figura 6. Indicadores de Sustentabilidade Propostos no PDI da UFRN. Fonte: Plano de Gestão (2019-2023), UFRN. 
Sobre os resultados das práticas implementadas pela UFRN, é importante analisar dois documentos principais que resumem o que fora desenvolvido no âmbito da sustentabilidade socioambiental da instituição, sendo eles: i) Relatório de Gestão (2019); e ii) Relatório Anual de Execução do Plano de Gestão de Logística Sustentável da UFRN (2019). A partir da análise sistemática de tais relatórios, foram consolidadas as principais iniciativas que esta instituição vem desenvolvendo e tendo notoriedade na temática ambiental, contemplando os eixos da Energia Elétrica, Água e Esgoto, Coleta Seletiva, Arborização, Obras Sustentáveis e Compras e Contratações.

Em se tratando da qualidade da água, a UFRN possui o Programa de controle de qualidade da água (Pró-Água), desenvolvido sob a coordenação da Superintendência de Infraestrutura e tendo a função de monitorar a qualidade da água fornecida à comunidade universitária por meio de coleta e análise periódica. Destaca-se também que a UFRN possui coleta e tratamento universal de esgotos domésticos no Campus Central e adota o reuso destes efluentes para irrigação dos campos de futebol do parque poliesportivo e da vegetação no entorno de sua Estação de Tratamento de Esgotos (ETE).

Relativo à gestão de resíduos, é desenvolvido o Programa de Gestão Integrada de Resíduos (PROGIRES) que consiste em um conjunto de projetos, ações, planos e normas destinados a promover e regular a concepção, implementação e administração do gerenciamento dos resíduos gerados na UFRN, permitindo a coleta, armazenamento, tratamento e destinação final dos resíduos gerados na Universidade. Em atendimento ao Decreto no 5.940/2006, a UFRN possui ainda a Coleta Seletiva Solidária que segrega e encaminha anualmente mais de 100 toneladas de resíduos sólidos recicláveis a uma cooperativa e a uma associação de catadores de materiais recicláveis do município de Natal.

Na dimensão da arborização da instituição, destaca-se a implementação do Programa de Arborização (PROÁRVORE), o qual permite a produção de mudas nativas da Mata Atlântica e Caatinga e o seu posterior plantio e manutenção, aumentando a área verde existente e melhorando a qualidade ambiental percebida. Para 2019, o Plano de Ação de Arborização objetivou implementar sistema de manutenção das árvores existentes, propondo uma meta de capacitar 50 pessoas, entre servidores e terceirizados, para a prevenção de acidentes envolvendo arborização. A ação foi executada em 12 de novembro de 2019, por meio de um minicurso que compreendeu um público de 55 pessoas, superando a meta prevista.

No quesito construções sustentáveis e eficiência energética, a UFRN adota diversos critérios, práticas e diretrizes para a promoção dos princípios da sustentabilidade no desenvolvimento de projetos de arquitetura, visando o uso inteligente da energia elétrica, atentando ao desenvolvimento econômico equilibrado. A instituição desenvolve o Programa de Eficiência Energética que tem como atribuições, dentre outras demandas, a implantação e o acompanhamento de projetos de eficientização de energia com melhorias do tipo de iluminação bem como das estruturas utilizadas visando economia de energia e melhora da segurança, e a adequação das instalações de baixa e média tensão existentes às normas técnicas vigentes.

A universidade também possui um Programa de Educação Ambiental (PROEA), que visa proporcionar à comunidade universitária fundamentação e capacitação para o desenvolvimento de uma relação de interdependência sociedade/natureza, conduzindo à adoção de uma postura responsável perante as questões ambientais. São realizadas feiras, oficinas e outros eventos, no sentido de sensibilização da comunidade universitária, tais como exposições interativas e itinerantes, cine ambiental, cesta ecológica, expedições e conhecendo a ETE.

Além das iniciativas anteriormente mencionadas, existe o aperfeiçoamento na coordenação de fluxo de materiais, de serviços e de informações, do fornecimento ao desfazimento, de modo a considerar a proteção ambiental, a justiça social e o 
desenvolvimento econômico equilibrado. Citam-se a racionalização, inventário físico, compra compartilhada, reutilização de bens, programa de qualidade de vida no trabalho etc. A UFRN mantém atualizado seu inventário de bens e materiais, buscando aperfeiçoar as especificações para aquisições de produtos similares que possuam menor impacto ambiental. Ainda com relação às aquisições e contratações sustentáveis, com fundamento no Decreto no 7.746/2012, informa-se que já são exigidos critérios de sustentabilidade em licitações na modalidade Pregão. A seguir, agrupa a síntese desses elementos, demonstrando alguns resultados quantitativos (Tabela 1).

Tabela 1. Ações de sustentabilidade implementadas pela UFRN.

\begin{tabular}{|c|c|c|}
\hline EIXO & INICIATIVAS PROPOSTAS & PRINCIPAIS RESULTADOS \\
\hline 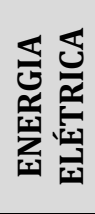 & $\begin{array}{l}\text { - Racionalizar o consumo de } \\
\text { energia e aumentar sua } \\
\text { eficiência nos ambientes da } \\
\text { UFRN; }\end{array}$ & $\begin{array}{l}\text { - Desenvolvimento de um módulo nos Sistemas SIG-UFRN } \\
\text { de acompanhamento e análise das faturas de energia } \\
\text { fornecidas pela COSERN (ODS 07,09,11 e 12); } \\
\text { - Realização de campanha de sensibilização sobre a redução } \\
\text { do consumo da energia elétrica na UFRN (ODS 03,11 e 12). }\end{array}$ \\
\hline 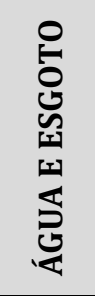 & $\begin{array}{l}\text { - Promover o uso racional da } \\
\text { água garantindo sua qualidade } \\
\text { e disponibilidade nos } \\
\text { ambientes da UFRN; } \\
\text { - Garantir o tratamento e } \\
\text { reuso do efluente gerado na } \\
\text { UFRN. }\end{array}$ & $\begin{array}{l}\text { - Atendimento em } 100 \% \text { as requisições para análise da } \\
\text { qualidade da água (ODS } 06,11 \text { e } 12 \text { ); } \\
\text { - A UFRN possui coleta e tratamento universal de esgotos } \\
\text { domésticos no Campus Central; } \\
\text { - Reuso de efluentes para irrigação dos campos de futebol } \\
\text { do parque poliesportivo, gerando uma economia de mais de } \\
300.000 \mathrm{~m}^{3} \text { de água potável ao ano. }\end{array}$ \\
\hline 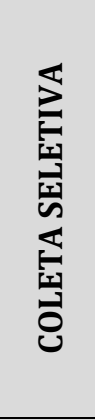 & $\begin{array}{l}\text { - Promover a gestão integrada } \\
\text { dos resíduos sólidos } \\
\text { produzidos da UFRN; } \\
\text { - Incentivar e apoiar a } \\
\text { realização de eventos na } \\
\text { UFRN que tratem de questões } \\
\text { relacionadas à gestão de } \\
\text { resíduos e sustentabilidade. }\end{array}$ & $\begin{array}{l}\text { - Temática da sustentabilidade da UFRN inserida nas } \\
\text { atividades oferecidas de recepção aos alunos e servidores } \\
\text { (ODS 03,06,11e12); } \\
\text { - Em 2018, foram doadas aproximadamente } 64 \text { toneladas de } \\
\text { material reciclável da UFRN. } \\
\text { - Em se tratando dos resíduos químicos laboratoriais, } \\
\text { considerados perigosos de acordo com a NBR 10004/2004, } \\
\text { estes foram coletados e encaminhados à destinação } \\
\text { ambientalmente adequada, totalizando cerca de 97,65 } \\
\text { toneladas, no período de } 2011 \text { a } 2018 \text {. }\end{array}$ \\
\hline 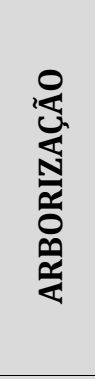 & $\begin{array}{l}\text { - Aumentar o número de } \\
\text { espécies arborescentes por } \\
\text { unidade de área; } \\
\text { - Implementar sistema de } \\
\text { manutenção das árvores } \\
\text { existentes; } \\
\text { - Enriquecer a diversidade de } \\
\text { espécies nativas existentes no } \\
\text { ambiente urbanizado. }\end{array}$ & $\begin{array}{l}\text { - Foram plantadas } 189 \text { árvores no campus central, todas } \\
\text { espécies nativas (ODS 03,11,13 e 15); } \\
\text { - Monitoramento em diversos aspectos que envolvem o } \\
\text { sistema arbóreo existente na Universidade, desenvolvendo } \\
\text { atividades de produção (coleta de sementes, produção de } \\
\text { mudas etc.), manutenção (podas, transplantios etc.) e apoio } \\
\text { no licenciamento ambiental. }\end{array}$ \\
\hline 赵 & $\begin{array}{l}\text { - Aplicar os princípios de } \\
\text { sustentabilidader no } \\
\text { desenvolvimento dos projetos } \\
\text { de arquitetura } \\
\text { complementares, visando a } \\
\text { eficiência energética, } \\
\text { racionalização do consumo de } \\
\text { água e a racionalização das } \\
\text { construções; }\end{array}$ & $\begin{array}{l}\text { - Projetos de edificações dotados de condições de receber } \\
\text { sistemas de energia fotovoltaica (ODS 03,07,09,11,12 e 15); } \\
\text { - Projetos de edificações dotados de condições de } \\
\text { reaproveitamento de água da chuva (ODS 03,06, } \\
09,11,12,13 \text { e 15). }\end{array}$ \\
\hline
\end{tabular}

Rev. Bras. Gest. Amb. Sustent., 2021, vol. 8, n. 20, p. 1333-1347. 
Tabela 1. Continuação.

\begin{tabular}{|c|c|c|}
\hline 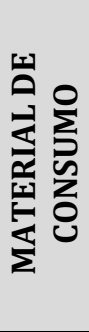 & $\begin{array}{l}\text { - Otimizar a aquisição e a } \\
\text { utilização de papéis do grupo } \\
\text { de materiais de expediente. }\end{array}$ & $\begin{array}{l}\text { - Cadastro de papéis atualizado, inserindo critérios de } \\
\text { sustentabilidade ambiental (ODS 12); } \\
\text { - Redução de } 58 \% \text { do consumo de copos descartáveis em } \\
\text { relação à média dos últimos três anos; } \\
\text { - Redução de } 34 \% \text { do consumo de papéis, do grupo material } \\
\text { de expediente, bem como aumento na proporção de } 13 \% \\
\text { para } 53 \% \text { do uso de papel reciclado em relação ao branco, } \\
\text { no tocante à média dos últimos três anos. }\end{array}$ \\
\hline 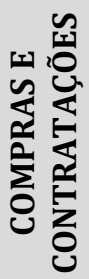 & $\begin{array}{l}\text { - Adquirir equipamentos de } \\
\text { refrigeração com melhor } \\
\text { eficiência energética; } \\
\text { - Capacitar servidores sobre } \\
\text { aquisições e contratações de } \\
\text { serviços sustentáveis. }\end{array}$ & $\begin{array}{l}\text { - Aquisição de equipamentos de refrigeração com melhor } \\
\text { eficiência energética: refrigeradores, freezers, geláguas e } \\
\text { condicionadores de ar (ODS 12); } \\
\text { - Realização de cursos de capacitação acerca das aquisições } \\
\text { e contratações sustentáveis (ODS 12). }\end{array}$ \\
\hline
\end{tabular}

Conforme evidenciado, a trajetória da UFRN remete ao desenvolvimento de diversas práticas que possibilitam uma melhor utilização dos recursos naturais, bem como a diminuição do impacto ambiental das suas ações, tendo a instituição adotado diversos critérios, práticas e diretrizes para a promoção da sustentabilidade na sua gestão.

Essas iniciativas levaram ao reconhecimento de algumas práticas que foram consideradas importantes e inovadoras no que diz respeito à gestão operacional da instituição, inclusive com recebimento de premiações. Esse é o caso da gestão integrada de resíduos da UFRN que foi classificada entre as dez finalistas do 1o Prêmio ODS BRASIL 2018, na categoria Instituições de Ensino, Pesquisa e Extensão, tendo recebido uma menção honrosa. Esse Prêmio ODS Brasil tem por objetivo incentivar, valorizar e dar visibilidade a práticas que contribuam para o alcance dos objetivos e metas da Agenda 2030 para o desenvolvimento sustentável no território brasileiro. 0 Prêmio busca contribuir, também, para a formação de um "banco de práticas" que servirá de referência na implementação e disseminação da Agenda 2030.

Além dessa prática, a UFRN também foi selecionada entre as 10 finalistas na categoria Instituição de Ensino, Pesquisas e Extensão com o projeto "Horta Comunitária Nutrir: educação para o desenvolvimento sustentável na formação em alimentação e nutrição-UFRN". A ONU reconheceu a prática como uma iniciativa que colabora para a promoção da alimentação como direito humano. A Horta Comunitária Nutrir busca conciliar o conceito de diversidade biológica com o de diversidade cultural, dando ênfase ao consumo de alimentos saudáveis produzidos pela agricultura familiar em circuitos curtos de produção.

Apesar de todo o avanço e do desenvolvimento de diversas iniciativas, é importante reconhecer que ainda se apresentam alguns desafios para consolidação dos princípios de sustentabilidade no ambiente de gestão da universidade. De acordo com a ex-reitora Ângela Paiva, se faz necessário promover uma maior adesão da comunidade universitária às ações que são propostas, de modo que esses atores sejam sensibilizados e façam adesão a esses conceitos no seu cotidiano de trabalho.

O movimento sustentável perpassa, portanto, pela ordem da cultura organizacional, iniciando-se no ambiente interno e sendo disseminado para todo o ambiente externo. Engelman et al. (2009) reforçam essa concepção, destacando a necessidade de se criar um consenso entre todos os níveis da organização acerca da importância da adoção dos princípios da sustentabilidade, os quais não devem apenas 
estar circunscritos em planos e documentos, mas, acima de tudo devem estar integrados com as funções desempenhadas pelos servidores. 0 comprometimento e o engajamento são, nesse sentido, fatores primordiais para que uma instituição seja considerada ambientalmente sustentável. Outro elemento que merece destaque é a necessidade proeminente de comunicar as ações de sustentabilidade que são desenvolvidas, fazendo com que, todos os atores da instituição, tenham conhecimento das práticas que são implementadas e se sintam parte desse movimento em busca de um futuro menos prejudicial ao meio ambiente.

É preciso superar as barreiras que impedem as instituições de ensino superior de implementarem seus sistemas de gestão ambiental, sendo desenvolvidas ações que busquem minimizar a falta de informação sobre as práticas sustentáveis, a não valorização do meio ambiente pelos servidores e colaboradores e a não percepção da universidade como uma fonte potencial de poluição (Tauchen e Brandli, 2006).

Engelman et al. (2013) também apontam outros elementos que devem ser verificados, destacando que os principais desafios para implementação de práticas de gestão ambiental nas universidades estão atrelados com a falta de recursos humanos e financeiros, dificuldade de conscientização dos servidores e até mesmo a falta de interesse das instituições de ensino. Para superar essas questões, as instituições devem reconhecer o grande passivo ambiental que possuem, passando a incorporar o desenvolvimento sustentável no rol de execução de suas ações. Além de desenvolverem pesquisas e fomentarem o ensino da temática ambiental, cabe a essas organizações tornarem-se espaços institucionais onde prevaleça a eliminação de desperdícios e a redução de consumo de recursos naturais (Tauchen e Brandli, 2006).

\section{Considerações finais}

O presente artigo retratou a experiência da Universidade Federal do Rio Grande do Norte (UFRN) no processo de implementação de práticas sustentáveis em sua gestão operacional. Ficou evidenciado que, desde 2003, a UFRN vem investindo em recursos humanos e financeiros para minimizar os impactos negativos ao meio ambiente causados a partir das suas atividades de ensino, pesquisa e extensão. Essa realidade ganhou mais notoriedade no ano de 2010, quando a instituição passou a incluir a sustentabilidade como pilar estratégico em seus documentos e normativos.

Atualmente, se observa que a instituição possui um planejamento capaz de propor práticas de sustentabilidade que são refletidas no cotidiano dos servidores, tais como indicadores de redução de consumo de papel, reuso da água, reaproveitamento de materiais de expediente, reciclagem de resíduos sólidos e eficientização energética. A própria missão da universidade passou a refletir essa preocupação com o meio ambiente, orquestrando as iniciativas que antes eram realizadas de maneira isolada.

Essa atuação reforça o papel central a ser desempenhado pelas instituições de ensino, as quais devem espelhar boas práticas e demonstrar que o desenvolvimento sustentável é uma alternativa não só desejável, mas viável. As universidades são, portanto, atores indispensáveis para transformação desse modo de utilização dos recursos naturais, podendo as suas experiências servirem como modelo a ser seguido por outras instituições.

A partir da análise dos documentos disponibilizados pela instituição, ficou clara a preocupação da universidade em garantir que os princípios de sustentabilidade propostos pela ONU e pelos demais organismos sejam incutidos no desenvolvimento de todas as atividades que são realizadas.

Sensibilizar e engajar os servidores, se traduz, nessa perspectiva, no principal desafio de operacionalização da temática nessas instituições. Conforme apontado em entrevista, identifica-se que apenas quando todos tiverem a consciência de que os recursos não são ilimitados, é que será possível, de fato, alcançar pilares da 
sustentabilidade socioambiental. Nesse sentido, além das ações que são propostas, as universidades devem estar atentas para o desenvolvimento de programas internos de conscientização, tornando as políticas ambientais prioridade em sua gestão.

Por fim, ao focar essa temática , este artigo proporcionou uma discussão sobre o tema, somando esforços às demais publicações no sentido de contribuir para 0 desenvolvimento de universidades ambientalmente sustentáveis. Por se tratar de um estudo qualitativo, a pesquisa possui limitações em sua natureza, porém sem comprometer os seus resultados que colaboram para a formação de um panorama atual sobre práticas de sustentabilidade ambiental desenvolvidas por universidades. Conclui-se que examinar essas experiências é reconhecer os desafios e perspectivas que se apresentam a essas instituições de ensino, disseminando boas práticas e fomentando a criação de diretrizes e modelos que devem ser seguidos como padrão pelas universidades e organizações que buscam se tornar referência na forma como lidam com o meio ambiente.

\section{Conflito de interesses}

Os autores declaram não haver conflito de interesses.

\section{Referências}

ABNT - Associação Brasileira de Normas Técnicas . ABNT NBR ISO 14001:2015 Sistemas da gestão ambiental - Requisitos com orientações para uso . Rio de Janeiro: ABNT, 2004.

Alves, G. C.; Oliveira Júnior, A. F.; Duarte, N. F. Modelos de Implantação de Sistemas de Gestão Ambiental em Instituições Públicas de Ensino Superior: uma Revisão Sistemática. Anais do IV Seminário dos Estudantes de Pós-Graduação (IFMG). Bambuí, 2018. Disponível em: <https://www.bambui.ifmg.edu.br/portal/images/PDF/SEP_2018/ Trabalhos_Completos/Modelos_de_implantação_de_sistemas_de_gestão.pdf>. Acesso em: 04 jun. 2021.

Barbieri, J. C.; Cajazeira, J. E. R. Responsabilidade social empresarial e empresa sustentável: da teoria à prática. 2. ed. São Paulo: Saraiva, 2012.

Couto, J.M. N. Motivações e barreiras na implementação de sistemas de gestão ambiental nas universidades. Porto: Faculdade de Economia do Porto, 2016. (Dissertação de mestrado).

Engelman, R.; Guisso, R. M.; Fracasso, E. M. Ações de gestão ambiental nas instituições de ensino superior: o que tem sido feito. Revista de Gestão Social e Ambiental, v. 3, p. 22 33, 2009.

Ferranti, M. P.; Jabbour, C. J. C. Instituições de Ensino Superior na transição para uma sociedade ambientalmente mais sustentável: grandes temas em debate à luz do conceito de sistema de gestão ambiental. Educação Ambiental em Ação, v. 10, n. 39, p. 1-9, 2012.

Fonseca Filho, L. F.; Bogdezevicius, C. R.; Faganello, C. R. F. Gestão ambiental nas instituições de ensino superior: uma análise da Universidade Federal do Sul da BahiaUFSB. Revista de Administração do Cesmac, v. 1, p. 16-44, 2018.

Gazzoni, F.; Scherer, F. L.; Hahn, I. S.; Carpes, A. M.; Santos, M. B. O papel das IES no desenvolvimento sustentável: estudo de caso da Universidade Federal de Santa Maria. Revista Gestão Universitária na América Latina, v. 11, p. 48-70, 2018. https://doi.org/10.5007/1983-4535.2018v11n1p48 
Gil, A. C. Como elaborar projetos de pesquisa. 4. ed. São Paulo: Atlas, 2018.

Guimarães, C.S.; Bonilla, S. H. O papel das práticas da universidade sustentável na construção das cidades inteligentes e sustentáveis. South American Development Society Journal, $\quad$ v. 4, p. 102-117, 2018. https://doi.org/10.24325/issn.24465763.vespi1p102-117

Lara, P. Sustentabilidade em instituições de ensino superior. Revista Monografias Ambientais, v. 7, p. 1646-1656, 2012. https://doi.org/10.5902/223613085341

Machado, R.; Fracasso E.; Tometich, P.; Nascimento, L. Práticas de gestão ambiental em universidades brasileira. Revista de Gestão Social e Ambiental, v. 7, n. 3, p. 37-51, 2013.

Nolasco, F. R.; Tavares, G. A.; Bendassolli, J.A. Implantação de programas de gerenciamento de resíduos químicos laboratoriais em universidades: análise crítica e recomendações. Engenharia Sanitária e Ambiental, v. 11, n. 2, p. 118-124, 2006. https://doi.org/10.1590/S1413-41522006000200004

Oliveira, P. F. R.; Oliveira, B. F.; Rohrich, S. S. Sustentabilidade em instituições de ensino superior: um revisão sobre as conferências internacionais para a sustentabilidade em IES . Anais do VIII Encontro Internacional sobre gestão Empresarial e Meio Ambiente, São Paulo, 2016. Disponível em: <http://engemausp.submissao.com.br/18/anais/arquivos/ 242.pdf>. Acesso em: 04 jun. 2021.

Pegorin, M. C.; Santos, D. C. D.; Martins, I. D. S. C. A aplicação da agenda ambiental no setor público: estudo de caso em uma instituição da administração pública federal direta. Anais do X Congresso Nacional de Excelência em Gestão. Rio de Janeiro, 2014. Disponível em: <https://repositorio.uniceub.br/jspui/handle/235/8925>. Acesso em: 04 jun. 2021.

Rohrich, S. S.; Takahashi, A. R. W. Sustentabilidade ambiental em instituições de ensino superior, um estudo bibliométrico sobre as publicações nacionais. Gestão \& Produção, v. 26, n. 2, p. 1-13, 2019. https://doi.org/10.1590/0104-530X2861-19

Salviano, M. C. M.; Araújo-de-Almeida, E.; Souza, M. D. F.; Medeiros, P. I. S.; D’Oliveira, R. G. Percepção ambiental de grupos sociais sobre a Agenda Ambiental na Administração Pública (A3P) em uma instituição de ensino superior, no Nordeste do Brasil. Brazilian Journal of Development, v. 6, n. 8, p. 9397-59411, 2020. https://doi.org/10.34117/ bjdv6n8-382

Santa, S. L. B.; Pfitscher, E. D. Universidade sustentável: análise internacional sobre a temática na literatura científica. Revista Ibero-Americana de Ciências Ambientais, v. 7, n 3, p. 229-243, 2016. https://doi.org/10.6008/SPC2179-6858.2016.003.0018

SDSN - Sustainable Development Solutions Network. Getting started with the SDGs in universities: A guide for universities, higher education institutions, and the academic sector. Australia: New Zealand and Pacific Edition. Sustainable Development Solutions Network - Australia/Pacific, Melbourne, 2017. Disponível em: <https://ap-unsdsn.org/ wp-content/uploads/University-SDG-Guide_web.pdf>. Acesso em: 04 jun. 2021.

Silva, G. S.; Almeida, L. A. Indicadores de sustentabilidade para instituições de ensino superior: uma proposta baseada na revisão de literatura. Revista de Gestão Ambiental e Sustentabilidade, v. 8, p. 123-144, 2019. https://doi.org/10.5585/geas.v8i1.13767

Souto, R. S. Sustentabilidade ambiental na Universidade de Brasília sob a perspectiva do UI GREENMETRIC. Brasília: Universidade de Brasília, 2020. (Dissertação de mestrado).

Tauchen, J.; Brandli, L. L. A. A gestão ambiental em instituições de ensino superior: modelo para implantação em campus universitário. Gestão \& Produção, v. 13, n. 3, p. 503-515, 2006. https://doi.org/10.1590/S0104-530X2006000300012

Rev. Bras. Gest. Amb. Sustent., 2021, vol. 8, n. 20, p. 1333-1347. 
Termignoni, L. D. Framework de sustentabilidade para Instituições de Ensino Superior Comunitárias. Porto Alegre: Pontifícia Universidade Católica do Rio Grande do Sul, 2012. (Dissertação de mestrado).

Treml, C.; Santos, E.; Santos, K.; Godoy, L. Desenvolvimento sustentável de universidades: um estudo comparativo entre Brasil e Venezuela. Revista Metropolitana de Sustentabilidade, v. 8, n. 3, p. 70-89, 2018.

UFRN - Universidade Federal do Rio Grande do Norte. I Relatório Anual de Execução do Plano de Gestão de Logística Sustentável. Natal: UFRN, 2019. Disponível em: <https://www.ufrn.br/resources/documentos/planos/pls/relatorio_de_atividades_PLS_2 019.pdf>. Acesso em: 04 jun. 2021.

UFRN - Universidade Federal do Rio Grande do Norte. Plano de Desenvolvimento Institucional 1999-2008. Natal: UFRN, 1999. Disponível em: <https://www.ufrn.br/ resources/documentos/pdi/PDI-1999-2008.pdf>. Acesso em: 04 jun. 2021.

UFRN - Universidade Federal do Rio Grande do Norte. Plano de Desenvolvimento Institucional 2010-2019. Natal: UFRN, 2010. Disponível em: <https://www.ufrn.br/ resources/documentos/pdi/PDI-2010-2019-final.pdf>. Acesso em: 04 jun. 2021.

UFRN - Universidade Federal do Rio Grande do Norte. Plano de Desenvolvimento Institucional 2020-2029. Natal: UFRN, 2020. Disponível em: <https://www.ufrn.br/ resources/documentos/pdi/Minuta-PDI-link-sugestoes.pdf>. Acesso em: 04 jun. 2021.

UFRN - Universidade Federal do Rio Grande do Norte. Plano de Gestão de Logística Sustentável. Natal: UFRN, 2017. Disponível em: <https://www.ufrn.br/resources/ documentos/planos/pls/plano_de_Gestao_de_Logistica_Sustentavel-PLS.pdf $>$. Acesso em: 04 jun. 2021.

UFRN - Universidade Federal do Rio Grande do Norte. Plano de Gestão 2019-2023. Natal: UFRN, 2019. Disponível em: <https://www.ufrn.br/resources/documentos/ planodegestao/Plano_de_Gestao_2019-2023.pdf>. Acesso em: 04 jun. 2021.

UFRN - Universidade Federal do Rio Grande do Norte. Política ambiental. Natal: UFRN, 2018. Disponível em: <https://www.ufrn.br/resources/documentos/politicas/politica_ Ambiental.pdf>. Acesso em: 04 jun. 2021.

Vaz, C. R.; Fagundes, A. B.; Oliveira, I. L.; Kovaleski, J. L.; Selig, P. M. Sistema de gestão ambiental em instituições de ensino superior: uma revisão. Gestão de Produção, Operações e Sistemas, v. 5, n. 3, p. 45-58, 2010.

Velazquez, L.; Murguia, N.; Platt, A.; Taddei, J. Sustainable university: What can be the matter? Journal of Cleaner Production, v. 14, n.9/11, p. 810-819, 2006. https://doi.org/10.1016/j.jclepro.2005.12.008

Yin, R. K. Case study research: Design and methods. 4. ed. Thousand Oaks, CA: Sage, 2009.

Zulpo, M.; Moraes, A. B.; Tedesco, C. D. Universidades e as dimensões da sustentabilidade: econômica, social e ambiental, uma revisão bibliográfica. Revista Ibero-Americana de Ciências Ambientais, v. 11, n. 4, p. 406-415, 2020.

Informação da Licença: Este é um artigo Open Access distribuído sob os termos da Licença Creative Commons Attribution, que permite uso irrestrito, distribuição e reprodução em qualquer meio, desde que a obra original seja devidamente citada. 